\title{
Making explicit in design education: generic elements in the design process
}

Citation for published version (APA):

van Dooren, E., Boshuizen, E., van Merrienboer, J., Asselbergs, T., \& van Dorst, M. (2014). Making explicit in design education: generic elements in the design process. International Journal of Technology and Design Education, 24(1), 53-71. https://doi.org/10.1007/s10798-013-9246-8

Document status and date:

Published: 01/02/2014

DOI:

10.1007/s10798-013-9246-8

Document Version:

Publisher's PDF, also known as Version of record

Document license:

Taverne

Please check the document version of this publication:

- A submitted manuscript is the version of the article upon submission and before peer-review. There can be important differences between the submitted version and the official published version of record.

People interested in the research are advised to contact the author for the final version of the publication, or visit the DOI to the publisher's website.

- The final author version and the galley proof are versions of the publication after peer review.

- The final published version features the final layout of the paper including the volume, issue and page numbers.

Link to publication

\footnotetext{
General rights rights.

- You may freely distribute the URL identifying the publication in the public portal. please follow below link for the End User Agreement:

www.umlib.nl/taverne-license

Take down policy

If you believe that this document breaches copyright please contact us at:

repository@maastrichtuniversity.nl

providing details and we will investigate your claim.
}

Copyright and moral rights for the publications made accessible in the public portal are retained by the authors and/or other copyright owners and it is a condition of accessing publications that users recognise and abide by the legal requirements associated with these

- Users may download and print one copy of any publication from the public portal for the purpose of private study or research.

- You may not further distribute the material or use it for any profit-making activity or commercial gain

If the publication is distributed under the terms of Article $25 \mathrm{fa}$ of the Dutch Copyright Act, indicated by the "Taverne" license above, 


\title{
Making explicit in design education: generic elements in the design process
}

\author{
Elise van Dooren • Els Boshuizen · Jeroen van Merriënboer • \\ Thijs Asselbergs $\cdot$ Machiel van Dorst
}

Published online: 30 August 2013

(C) Springer Science+Business Media Dordrecht 2013

\begin{abstract}
In general, designing is conceived as a complex, personal, creative and openended skill. Performing a well-developed skill is mainly an implicit activity. In teaching, however, it is essential to make explicit. Learning a complex skill like designing is a matter of doing and becoming aware how to do it. For teachers and students therefore, it will be helpful to make the design process explicit. In this paper, a conceptual framework is developed to be more explicit about the design process. Based on research of the design process, on differences between novices and expert designers, and on personal experience in design education practice, five generic elements in the design process are distinguished: (1) experimenting or exploring and deciding, (2) guiding theme or qualities, (3) domains, (4) frame of reference or library, (5) laboratory or (visual) language. These elements are generic in the sense that they are main aspects and always present in the complex, personal, creative and open-ended design process.
\end{abstract}

Keywords Design process · Generic elements - Design education · Making explicit

E. van Dooren $(\square) \cdot$ T. Asselbergs $\cdot$ M. van Dorst

Faculty of Architecture, Delft University of Technology, Julianalaan 134, 2628 BL Delft,

The Netherlands

e-mail: E.J.G.C.vanDooren@tudelft.nl

T. Asselbergs

e-mail: M.F.Asselbergs@tudelft.nl

M. van Dorst

e-mail: M.J.vanDorst@tudelft.nl

E. Boshuizen

Open Universiteit, Valkenburgerweg 177, 6419 AT Heerlen, The Netherlands

e-mail: els.boshuizen@ou.nl

J. van Merriënboer

Department of Educational Development and Research, Maastricht University,

PO Box 616, 6200 MD Maastricht, The Netherlands

e-mail: j.vanmerrienboer@maastrichtuniversity.nl 


\section{Introduction}

A complex, personal, creative and open-ended skill

In general designing is conceived as a complex, personal, creative and open-ended skill. Dreyfus and Dreyfus (1986) label the design process as 'unstructured'. Lawson (2006) sees it as a 'prescriptive job', creating (some features of) the future. Schön (interviewed by Goldhoorn 1991) points out that designing is complex: it is about different kinds of knowledge, about developing a personal system of preferences, and about using a specific language of sketching and modelling. For experienced designers the process is not split up in separate steps and actions but the process is an undivided whole with automatic, unconscious steps, actions based on common practice or routine, and moments of reflection and exploration.

The question is how teachers can help students learn such a complex, personal, creative and open-ended skill like designing. How they can improve their teaching?

To answer these questions, we need to look deeper into the process of learning and designing. In this paper, in the first place, the importance of making explicit in teaching and learning is discussed, which generates another question: what teachers have to make explicit and what students have to become aware of in learning to design? In this paper, we suppose that spontaneous talk between teachers and students mainly regards the product but that a vocabulary for discussing the process is missing. To help making the design process explicit, a conceptual framework with five generic elements will be presented in this paper. After first defining the starting points and criteria and giving an overview of the framework, it will be worked out in more detail in the second section. In the concluding section it is discussed how teachers and students may benefit from this framework.

\section{Doing and making explicit}

Traditionally the 'designerly way of thinking' (Cross 2007) is learned in the studio. Designing is learned in a kind of master-apprentice system, or in educational terms: in a process of learning-by-doing.

In his studies on the architectural studio Schön $(1985,1987)$ pointed out the paradoxical character of design education. He stated that the student "is expected to plunge into the studio, trying from the very outset to do what he does not yet know how to do, in order to get the sort of experience that will help him learn what designing means" (Schön 1985: p. 57). For the student this is a confusing situation.

The teacher faces a similar problem. In principle, the teacher is an expert designer. However, in general, performing a skill like designing is largely an implicit activity (Dreyfus and Dreyfus 1986; Lawson 2006; Ryle 2002). For experienced designers it is often difficult to make explicit what they do and how they do it. Schön $(1985,1987)$ refers to this as "knowing-in-action", addressing the phenomenon that relevant knowing is only available by doing rather than thinking.

Yet, in the process of learning and teaching a complex skill like designing, making explicit and becoming aware how to do it are essential. In that respect it is similar to learning a sport, which is also a complex skill. Though mainly a matter of doing, the trainer explains and repeats the main principles while the learner is practicing. Dewey (Logister 2005) refers to this as "knowing is supporting to action". Knowing makes us understand the relation between our actions and their consequences. A better understanding of these relations helps the learner to focus better and act more thoughtfully, more intelligently. 
Especially in unknown and new situations, it is important to use this knowing. Also in the learning cycle of Kolb (1984) doing and making explicit are integrated. Kolb describes learning as meaningful when four phases are included: (1) concrete experience or 'feeling'; sensory perceptions of concrete objects, (2) reflection or 'watching'; observing and thinking, mental experimenting, (3) abstract understanding or 'thinking'; translating experiences in general notions, conceptualising, relating, and (4) active experimenting or 'doing'; physical experimenting. And Reigeluth (1999), in looking over the rich landscape of learning- and instruction theories, sees an overlap and establishes a difference in basic and variable methods. The variable methods are more specific and explain learning and instruction from different points of view. The basic methods are rooted in experience and have been proven effective. They enhance the learning process. Doing, explaining, showing, and providing feedback are basic learning methods in most learning and instruction theories.

Dewey, Kolb and Reigeluth suggest that learning a complex skill like designing is a continuous process of doing and making explicit. It is about acquiring habits and patterns that are mostly implicitly used by an expert designer. As a student you learn by doing and by becoming aware of how to do it. The learning process arises from largely implicit knowing and acting, includes making explicit and becoming aware, and results again in largely implicit knowing and acting (see Fig. 1).

However, the conclusion that making explicit is essential in the process of teaching and learning, does not answer the question as to what teachers have to make explicit, and what students have to become aware of in learning to design. To answer this question subjects or layers in the dialogue between teacher and student will be distinguished first.

From product to process; the development of a teaching tool

To help the student in the process of doing, the teacher and the student in a studio have regular talks. In the dialogue between teacher and student, Schön $(1985,1987)$ distinguishes two levels: in and about the design process. It is an intertwined process of language and meta-language. The language is about doing architecture: the teacher talks about architecture by drawing and explaining. The meta-language is about the process of

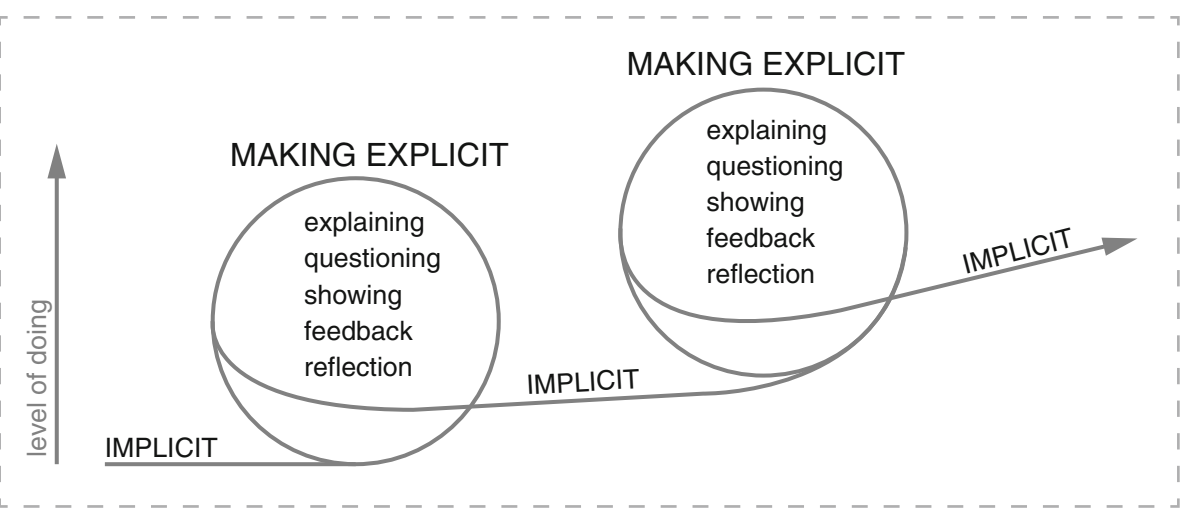

Fig. 1 Making the implicit explicit in learning 
designing. It describes features of the process demonstrated, and introduces reflection on the design action.

Here, more layers are distinguished and defined: (1) To become experienced designers, students learn by doing, by working on a case study: the design project at hand. (2) At the same time, they learn to apply personal and general knowledge, they learn about heuristics, rooted in experience and proven effective rules of thumb in the design field: the design principles. (3) Often implicitly, a teacher or student may follow a personal or cultural approach: a design method. (4) However, students study to become a designer; they have to learn about the generic elements in designing, going beyond the personal and cultural 'filling in' or expression: the design process.

Informal observations of design teachers at work suggest that student-teacher conversations mainly regard the product. Principles and methods are discussed less often, while the process is almost always left implicit.

In a design education course for design teachers, ${ }^{1}$ we try to make the levels of conversation mentioned above more tangible. The teachers carry out short design exercises, following by a role play (teacher, student and observer) to practice the teacher role.

In the spring of 2012, a group of 12 design teachers was given an assignment to design an easy chair in approximately $15 \mathrm{~min}$ in a paper/cardboard/wooden sticks model while thinking aloud. A 15 min workshop like this, with thinking aloud during the design process, is a simplified, accelerated and condensed design process. It illustrates many of the characteristics of a more complex design process. Later in this article, we will reflect on the design process observed.

In the present context, the role play - teachers practicing being a teacher, by playing the role of teacher and student - is very telling. Most of the dialogues between role-playing teachers and students were focussed on the design product only. The teachers questioned the students about the chair: Why do you make a 'collapsed' chair? Will this chair be a comfortable chair? For what kind of sitting is your chair meant? Why do you choose a soft material? Could it be another material? Is the material for a surfboard the right material for a chair? Why do you make this particular form?

In the protocol of a teaching conversation published by Schön $(1985,1987)$, the teacher seems to pay more attention to the design process. Schön concludes that the teacher conducts an experiment at a point where the student got stuck. However, also here, it seems to be more a teacher implicitly showing the process, not making the implicit explicit, not naming and explaining the process of designing. By mentioning notions such as geometry, L shape, broken open, screwy contours,... the teacher explicitly talks and draws about architecture, implicitly showing the process of experimenting, of making a move and exploring the consequences. Schön concludes similarly: The teacher "reflects very little on his own reflectionin-action, and it would be easy for a student or observer to miss the fundamental structure of inquiry which underlies his virtuoso performance" (Schön 1983: p.104).

In their studies about the design process Lawson and Dorst (2009), in respect to design education, conclude that they immediately 'feel at home' to a considerable extent, when teaching in design departments anywhere in the world. Because the way in which design is learned (and taught) seems to be the same in many fields and in many countries. Design education "relies heavily on project work, appears student-led, takes place in social context and explores and develops individual talent and creativity" (Lawson and Dorst 2009: p. 218). Defining major features of the core of design education, the design studio, they conclude that the studio is "the place where things happen, where knowledge can be found and advice

${ }^{1}$ Developed and given by Elise van Dooren and Luc Willekens, TU Delft. 
given" (Lawson and Dorst 2009: p. 226). Knowing integration to be essential in designing, they assume that the studio is so successful because of its integrative quality. At the same time they also question the way in which the studio works pedagogically, especially in respect to the integrative character: "It is somehow assumed that we must set projects demanding integration and that somehow students will achieve it" (Lawson and Dorst 2009: p. 234). Students are generally set a series of design projects, progressively more difficult. "However, most design schools still teach relatively little material in terms of the essential and central skills of designing that we have identified here. Students are simply expected to pick these up through a process of learning on the job as it were" (Lawson and Dorst 2009: p. 236).

Also Oxman (2001) concludes that traditionally design education is based on the replication of professional task performances and argues that, having developed a considerable body of cognitive design knowledge, it is needed to redefine the educational models from the production of design artefacts to an orientation on designerly thinking. In Oxman (2001: p. 273) words: "By contrast to the explicitness of knowledge which must become part of the design educational process, the design studio today is still characterized by the faults of product orientation, creative design as a black box, and the pedagogical distance of the tutor. In all of its institutions there is generally a lack of explicit definition of the requisite knowledge of design, and a neglect of attention to thinking in design as legitimate pedagogical content. Although there may be an integration of design concepts, formal skills and knowledge which are 'learned by practice' in the studio, the explicit learning of the cognitive content of design is ignored and left to be gained implicitly through experience."

These analyses lead to the conclusion that design teachers lack the concepts and vocabulary to make the design process explicit. Therefore, in this paper, a basic framework to make the design process explicit is described, distinguishing five generic elements in the design process. The framework is meant as a tool, which can be used in design education, to make the design process explicit in a more structured and clear way.

\section{Literature}

Starting point and foundation for defining generic elements is what researchers have written about the design process. Schön $(1985,1987)$ describes what happens in the design studio, and others like Darke (1979), Lawson (2004, 2006), Cross (2007) and Lawson and Dorst (2009) write about the design process in general.

Apart from substantiating the generic elements in research about the design process, it is important that they are defined from an educational point of view. Therefore literature on differences between novices and expert designers (Eastman et al. 2001) was studied.

The research studies about the design process and the differences between novices and expert designers, cover several disciplines. However, it is assumed that the different design disciplines have a lot in common (Cross 2001).

Rooted in literature and tested in educational practice, the generic elements are chosen and defined in an iterative process.

Before continuing, a remark has to be made. The research in this paper focuses on architectural design, but for reasons of readability, the shorter notions 'designing' and 'design process' are used. At the same time, the suggestion is made that the generic elements may be useful in different design disciplines. Research on the design process (Cross 2001) seems to point in that direction. So did discussions on the proposed framework in a design education network (TU Delft), in which several participants from different design disciplines meet regularly. 
Requirements

The following requirements for a workable educational framework for the design process were formulated:

In the first place, the elements have to be generic in the sense that they are almost always part of a design process, no matter how personal, complex, open-ended and creative the process is. The framework should describe the characteristic elements in the design process, beyond personal and cultural methods. And, in doing so, it should help in comparing the methods, seeing the similarities and the personal and cultural differences in emphasis and nuances.

In the second place, the generic elements should present a balance between the process followed by expert designers and the aspects students have to learn to become such expert designers. Students lack certain knowledge and skills expert designers have. Training students in those aspects is essential in learning to design.

In the third place the framework has to be clear and easy to remember. It should be a coherent and 'logical' or natural way of describing the design process. Designing being complex, students are often drowned in a chaotic approach to their design work. A clear overview may help students to come to grips with the process. The elements should help in talking about the design process in all its (main) aspects.

Informal observations, literature and the requirements formulated, resulted in the following conceptual framework.

\section{Framework}

The conceptual framework consists of the following elements (see Fig. 2):

1. The process of experimenting or exploring and deciding is a dialectical process of being open and alert, analyzing and associating, coming up with alternatives on the one hand and finding criteria, testing and evaluating on the other hand. It is a process of diverging and converging.

2. In the process of experimenting, one has to come up with an inspiring direction: a guiding theme or qualities as something to hold on to during the design process and to help create a coherent and consistent result.

3. The process of experimenting and coming up with a guiding theme takes place in different domains, or work fields. A designer has to make statements in all these domains. For architectural design these are: space, material, site, function and sociocultural context.

4. The design process is inseparably embedded in a broader context: a frame of reference or library. All knowledge is stored in the environment, in books and, often implicitly, in the designer's mind. The references provide patterns, diagrams, rules of thumb and solutions to be used in the experiments.

5. The design process has its own laboratory. For architectural design the laboratory consists of a visual language of sketching and modelling. The physical counterpart of the mental process is an external, extended memory and tool for reflection.

Designing is an interwoven process: the generic elements are to be distinguished, not separated. The generic elements are not meant as a recipe for the design process. They are general principles or common features, present in one form or another in any design process. The elements emerge in the design process, next to and interwoven with each other. There is no fixed step-by-step sequence, and the emphasis on and the way in which 

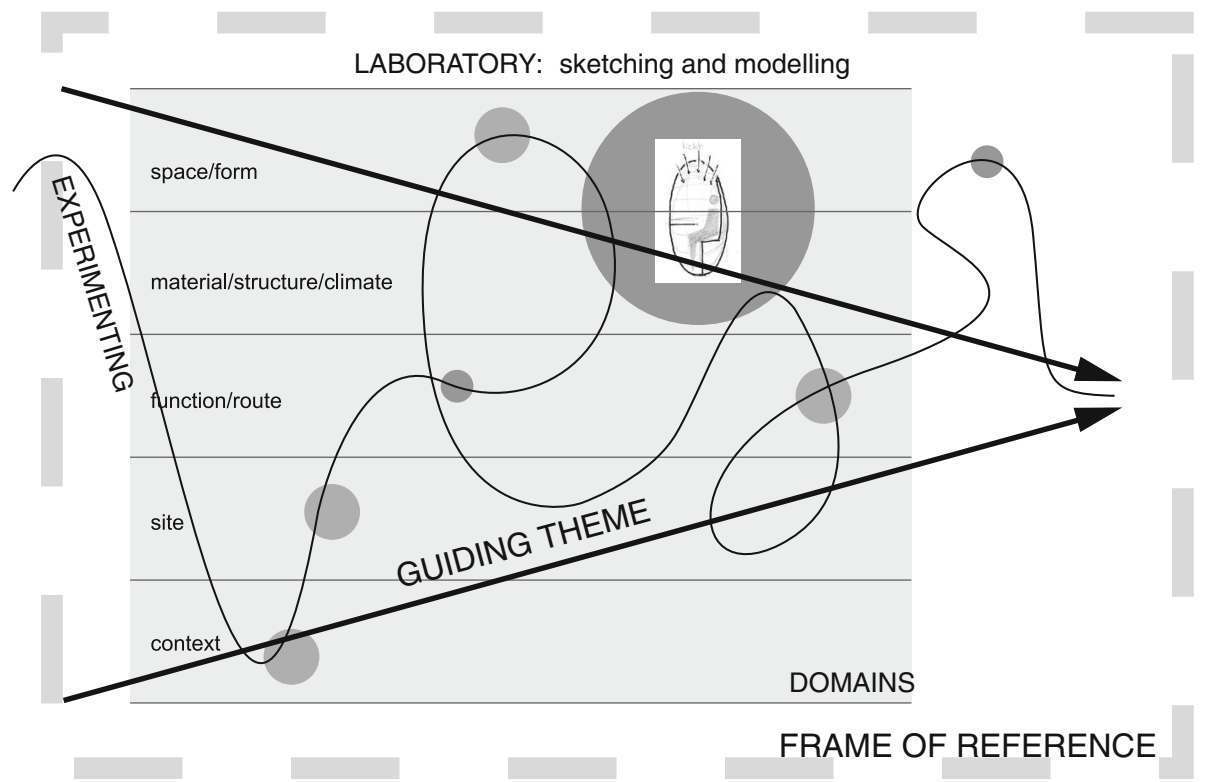

Fig. 2 The five generic elements in the design process: experimenting, guiding theme, domains, frame of reference and laboratory

the elements are filled in or 'coloured' differs, depending upon the kind of project, the designer and the design discipline.

\section{Generic elements}

In this section the generic elements will be worked out more in detail, starting by defining each element, including references to research on the design process. After that, the educational aspects will be discussed, including references to research on design education and, finally, the elements will be illustrated with examples from the $15 \mathrm{~min}$ 'design a chair' workshop.

\section{Experimenting or exploring and deciding}

The design process is a process of thinking in broad outlines and in detail, of doing and reflecting, of intensive work and taking distance, of naming and valuing, of questioning and answering, of diverging and converging, and of seeing what is and what could be there. It is a process of balancing between opening up possibilities, seeing new ways, analyzing, discovering alternatives, associating, encircling a subject and abstracting on the one hand and on the other hand reducing possibilities, testing, selecting, evaluating and making decisions. To summarize all these dialectical and often paradoxical actions: designing is first and foremost a process of exploring and deciding, of experimenting (see Fig. 3).

Designing is conducting experiments and learning about the consequences and implications of these experiments. Schön (1985) describes this process of conducting (small) experiments as 'experimenting' and as 'making a web of moves'. He defines the moves as changes in ideas and representations. The experiments or moves are evaluated and further 


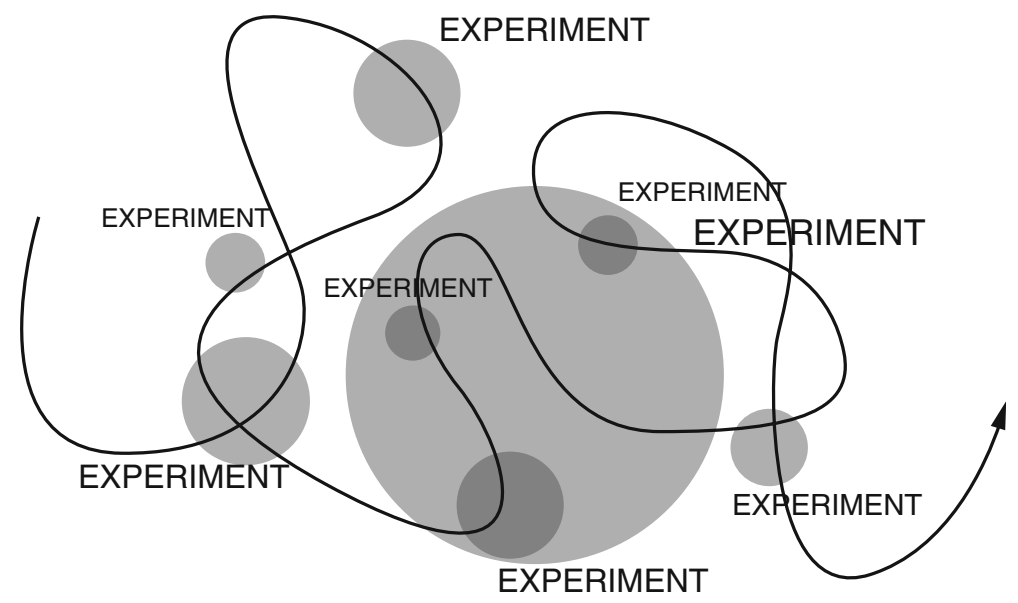

Fig. 3 Designing is experimenting: a process of exploring and deciding, of trial-and-error

experiments are conducted. Making moves means creating new problems to be described and solved. And making moves may serve in seeing things in a new way, in constructing new meanings and intentions.

Schön concludes that making a move in a situation may serve, at the same time, as testing a hypothesis, exploring phenomena, and affirming or negating the move. About the decision-making process Schön concludes: "the designer evaluates his moves in a threefold way: in terms of the desirability drawn from the normative design domains, in terms of their conformity to or violation of implications set up by earlier moves, and in terms of his appreciation of the new problems or potentials they have created" (Schön 1985: p. 49).

In a way the process of experimenting is a process of questioning or in Schön's words (1985) a 'reflective dialogue' and 'conversation with the situation'. The designer is exploring and testing in experiments or moves with questions like: What if I do this?, What do I have to do to achieve this?, What is happening here?, Do I like this?, Does it fit in with what I want to achieve?, Which criteria are important in this situation?

Researchers, like Cross and Dorst (Cross 2001), refer to this process of experimenting as well when they talk about a co-evolution of solution and problem spaces. They conclude that, for designers, the evaluation of the solution is more important than the analysis of the problem. Relatively early in the process the designer's attention shifts to possible solutions. Simultaneously with the exploring of data and features, the designer explores ideas and directions to solve the problem. Analysis and synthesis occur simultaneously.

Another perspective from which to look at the process of experimenting, is the process of creativity, of intensive work and taking distance. Poincaré (Boden 1990; Csikszentmihalyi 1996) distinguished four characteristic stages in creative processes: (1) preparation, a period of intensive work and studying, of consciously searching for an answer, (2) incubation, a period of taking distance, of working in the unconscious, (3) illumination, a moment of seeing the light, the 'eureka' and (4) verification or evaluation, a period of elaboration, conscious work, testing the new conceptual ideas. Lawson (2006) ascertains that being creative is not a matter of being novel and different. It is a matter of generating and testing alternatives, of transforming ideas, of using parallel lines of thought, and of accepting incomplete and possibly conflicting ideas coexisting, without attempting to resolve them too early in the process'. 
For students it is important to learn about the experimental character of designing: designing is about conducting experiments in an open and at the same time focused way. They may have all kind of misconceptions about the design process, such as being creative in a mystical sense or coming up with something logical based on a lot of analysed facts. They also often think they have to come up with 'perfect' solutions, solving all aspects and problems at once. They have to learn to be open and to consider designing as a step-by-step exploration, as experimenting, as a process of trial-and-error, of 'making mistakes' and learning from them.

In general, students work in a more linear way and are focused on one solution. Newstetter and McCracken (2001) observed among other characterizations of typical student behaviour, that students tend to stop considering alternatives, once they have an idea, and that students act as though designing is a linear, not an iterative process. Also Atman and Turns (2001) found that students might get stuck in scoping out the problem and spending much time (or too much uninterrupted time) in modelling a single solution.

Expert designers have more sophisticated skills in their exploration and in gathering and structuring information. They frame or perceive problems in terms of relevant solutions. In an overview of different research studies, Cross (2001) concludes that experts, being more experienced, have a better feeling for distinguishing relevant and irrelevant information. Their decision-making is based on more considerations. Students may become stuck in gathering lots of information, without moving on in the process of experimenting and testing of ideas. Experts move more rapidly to potential solutions and use these as a means to further explore and understand the problem.

For example a student is exploring a more or less chaotic site with different building masses and a park, to come up with a building 'fitting in with the context'. He analyses all building masses in the site, hoping this will logically lead to a fitting building mass. An expert designer, in this case the teacher, demonstrates the trial-and-error approach: putting a building mass in the site and testing what it brings about.

In the 15 min 'design a chair' workshop, at the outset, a process of experimenting or exploring and deciding started. Even in the short time available, the process consists of a series of small experiments. Often implicit, sometimes explicit, it looks like a process of questioning and answering. What if I do this? What do I want to achieve?

A designer who connected an easy chair to meditating, followed a train of thought like: 'For meditating a quiet, minimalistic space is needed.'/'A concrete block will do, in an enclosed, small garden with stones, some plants and a tree.'/'Some wood will be there as well, for: 'my partner doesn't like all the concrete and stone'.'

One of the designers asked himself: (1) 'is lying in the grass comfortable?' (2) 'what makes lying in the grass uncomfortable?' (3) 'what can we do to make lying in the grass (more) comfortable? and came up with the idea to make some kind of shape in the grass.

The interpretation of lounging as 'finding your way', sitting in a flexible, springy shape, led to the following train of thought: (1) So, it has to be a large, soft, massive volume, to use in all kinds of shapes. (2) 'However, I cannot make that in paper, so how can I produce something like it?' (3) 'I have to make a bended shape, on top of a resilient, zigzagging structure.' Then, in the process of making it, the designer concluded that it would be much better to integrate the resilient structure in the vaulted shape; he was very satisfied with the result. He now saw an open volume, soft on top, with a metal sheet inside. So a transformation took place from a massive to an open form, caused by the fact that making the chair in this particular situation was a difficult thing to do. This shows that, to a certain extent, designers may find themselves taken by surprise in the situation at hand. 


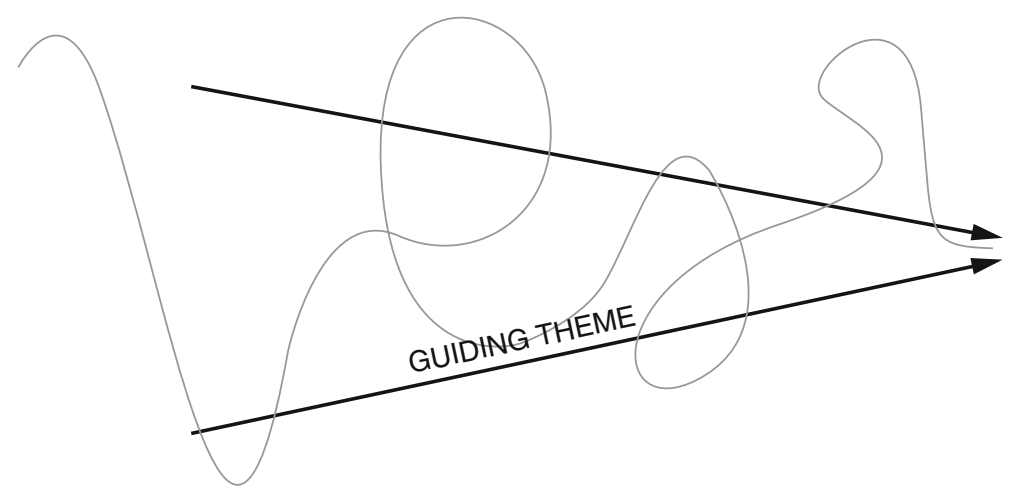

Fig. 4 Designing is developing a guiding theme: discovering qualities or imposing an order

Another designer made a transformation like that. She started with an egg shape as a protected seat for children. She struggled with the modelling material, and therefore came up with a more open shape, more like a flower with leaves. She liked it, because the enclosed feeling still remained, but at the same time more openness was achieved.

Guiding theme or qualities

Designing is exploring and deciding within a potentially endless number of possibilities, to come up, in the end, with an internally coherent whole. To be able to create a coherent whole, a designer needs an inspiring direction or order. Using a guiding theme or qualities not only gives the design its character and identity in the complex and open design process, it also helps in making choices (see Fig. 4). The guiding theme is the way in which the designer sees or frames the design situation at hand. Designing is a process of naming and framing, of attending to matters and of making a context to work with them.

Different researchers and designers name and describe the guiding theme in their own way. A colleague of the authors and very experienced design teacher, Robert Nottrot, ${ }^{2}$ asks students what 'qualities' they want to achieve. Schön $(1985,1987)$ describes designing as 'a situation of complexity and uncertainty which demands the imposition of an order' and as 'experimenting with a hypothesis'. He also writes about 'constructing an order', 'giving meaning' and 'naming and framing'. Darke (1979) calls it a 'primary generator', a 'relatively simple idea', a ground for making choices and for analyzing what the important aspects in the design are. According to Lawson (2006) working with two or more 'primary generators' is characteristic for the design process. Bielefeld and El Khouli conclude: "Every design begins with a search for an idea or for an intuitive understanding of how an assignment should be solved. This idea is the start of a long journey on which the designer defines the idea more precisely, modifies it, adds details and repeatedly rejects results" (2007: p. 7). Other phrases used are: organizing principle, parti, statement, pattern, paradigm, concept, conceptual drive, leitmotiv and guideline.

All the different phrases for what we call the guiding theme illustrate that the character of a guiding theme may vary. The guiding theme may be a quality, an image, a meaning, a material fascination, a functional theme or a kind of 'form language'. In fact different 'variations' often come together in the guiding theme. It would be better to describe the

2 Personal communication. 
guiding theme as a sequence, a 'train of thoughts', developing in time. For example: it may start with a meaning or quality, vague and abstract, and then gradually transforms into a more concrete, still open and multiple 'form language' to fill in. However, it can also take place in reverse order: starting with concrete facts or ideas about form, material or function, a meaning or quality is found and translated into other aspects. Lawson and Dorst write about the evolution of a solution: "The initial ideas can be seen as the first primitive objects, evolving and becoming more subtly tuned to the design problem over the generations" (2009: p. 36).

Working with a guiding theme may be schematised as the process of exploring to come up with one or some qualities and then exploring those qualities, transforming them in architectural means. In the fractal-like process of testing solutions, in the creative process of intensive work and taking distance, an overall guiding theme often seems to emerge; one or a few qualities occur as the main character of the design. The selection of proper, relevant or 'design problem fitting' guiding themes or qualities is subjective, but also based on cultural judgment. It is based on experience, on being part of and having in mind a 'designerly frame of references and inspirations', and on the choice of what is liked or seen as adequate in the particular context. Often the choice is determined by the situation at hand, the design task or problem. It may, however, also be a theme in which a designer has been interested for some time. Lawson (1994) refers to these themes as designers bringing their own intellectual programme with them into each project. Sometimes these programmes are result of a lifetime of study and development. They provide in a series of 'guiding principles'.

Students have to be trained not only in developing guiding themes, but also in really using them during the process. Moreover they have to study and experience different kinds of guiding themes, learn about their relevance and discover their personal fascination when choosing guiding themes.

In an overview, Cross (2001) refers to different studies showing that expert designers use guiding themes more intensively. They explore the guiding themes or concepts more rigorously and profoundly than starting designers. And because they are more experienced, they choose a relevant analogy more easily.

Newstetter and McCracken (2001) observed that students believe that proper designing is coming up with good ideas. Yet, expert designers are always concerned with the feasibility of ideas and they evaluate ideas based on informed decision-making analysis.

In the end the guiding theme is often recognizable in the character of a design result. Examples are the lack of perspective of the Jews in World War II in the Jewish museum in Berlin by Libeskind, the uplifted landscape in the university library in Delft by Mecanoo, the geometric harmony in the museum of arts and crafts in Frankfurt by Richard Meijer and the human eye in the arts and science center in Valencia by Calatrava. Examples in the discipline of industrial design are the user friendliness in the Apple products and the 'come back' of the unique handcrafted product in the industrial production of series in the work of Hella Jongerius.

Early in the process of the 15 min 'design a chair' workshop, the designers came up with a guiding theme or quality. A process of transformation or a 'train of thoughts' was started. In a process of reflecting about a 'good' easy chair and their own ideas about an easy chair, the participants came up with an association, a statement, an image or an idea.

One designer took 'easy chair' literally: she came up with the idea of a chair in an 'easy' posture. To another, an easy chair meant meditating. And a third designer saw sitting as a verb, so his chair would challenge the user to move. In this design task, no site was defined. However, designers in architecture often connect an assignment to a site and/or some 
specific use. Some designers did associate lounging or being idle with sitting or lying in the grass, in the sun or under a tree, together with someone else or alone with a glass of wine and a book. There was also a designer who connected the design of the chair with his home, which is situated in a barn and therefore has large, open spaces. The chair needed to offer the family members a protected place to sit in, in the openness of the large room.

\section{Domains}

The act of designing, of experimenting with a guiding theme, takes place in a work field, in the real world of shape and material, gravity and use; a designer works with physical elements. Putting it another way: the act of designing takes place within and across domains. To think and communicate about the concrete world, we use words, we categorize it. Schön (1987) calls these categories in architectural design, domains. "These domains contain the names of elements, features, relations and actions and of norms used to evaluate problems, consequences and implications" (Schön 1987: p. 58).

Depending on the design discipline, the domains differ. For architecture, Schön (1985) distinguishes relatively many (twelve) domains., They vary from program and site, building elements and organisation of space, to scale, costs, precedent and representation. By giving a general definition for architectural design here, an effort is made to give the domains the character of an overview and develop a common-sense and therefore relatively easy-to-remember order. 'Architectural design is about creating space and using material. The space is meant for use by a defined target group and is situated within a defined site and a socio-cultural context.' In line with this working definition, five main domains can be distinguished: (1) form and space, (2) material (3) function, (4) physical context, and (5) social, cultural, historical and philosophical context (see Fig. 5). In the different domains many aspects, such as composition, light, texture, climate and movement come together.

In the design process a lot of information in the different domains is involved. Experiments or moves are made in all domains and implications of moves are found in all domains. Schön and Wiggins (1992: p. 143) conclude: "a move informed by an intention, formulated within one domain, has consequences in all other domains. Because of our limited information processing capacity, we cannot, in advance of making a particular move, consider all the consequences and qualities we may eventually consider relevant to the situation." Designers have to deal with all this information. Lawson quotes Michael Wilford, who compares this complex work of a designer with a "juggler, who's got six balls in the air... and an architect is similarly operating on at least six fronts simultaneously and if you take your eye off one of them and drop it, you're in trouble." He concludes:

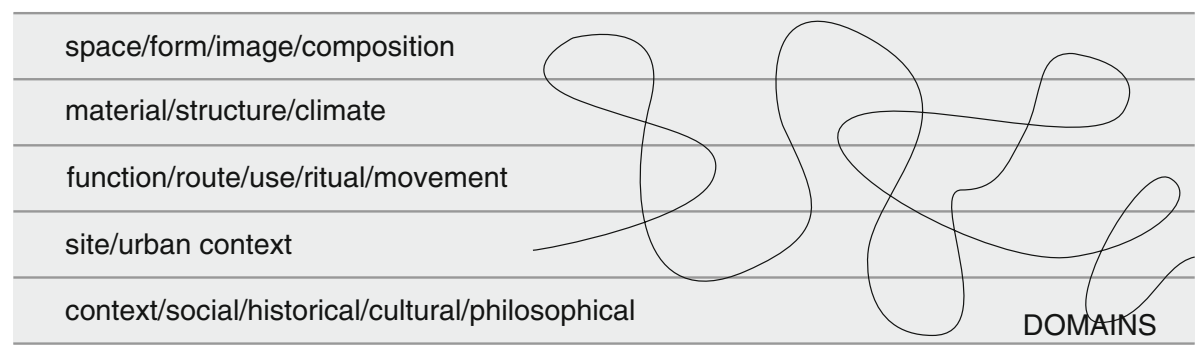

Fig. 5 Oscillating like a juggler, a designer has to make decisions in a lot of domains 
"The only way to keep them all in mind at once, as it were, is to oscillate very quickly between them like a juggler" (Lawson 2006: p. 151).

Students have to be trained in oscillating across the domains and in seeing relations between all aspects. Students tend to solve and finish the domains one by one, they often work in a linear sequence. Most expert designers make more transitions, they move more frequently across domains, cycling back and forth. An experienced designer seems to work simultaneously in several domains, the designer moves a lot across the domains. Cross (2001) concludes from several studies that expert designers and more successful students work across different domains. Especially during creative periods, these designers rapidly alternate the focus of their attention between different aspects or between different modes of activity.

An example of working within and across domains is designing the structural part in a building. Besides the aspects of stability and strength, aspects of availability and sustainability of material play a role and the structure often has an important relation to and influence on the spatial and functional order and routing. Students have to learn to see all aspects and relations and get an overview of all different aspects by experimenting across the domains, to be able to come up with integral decisions.

In the 'design a chair' workshop, even in the relatively short time of $15 \mathrm{~min}$, different domains were overviewed: form, function, material and site. Often designers started with an idea (or guiding theme) about sitting, lounging and the meaning of an easy chair, varying from a movable 'garden chair', to a place to meditate. These ideas were then developed into more real shapes and material. Also the functional aspects, such as sitting comfortably, became more real. A designer asked himself: 'what circumstances make sitting outside a relaxing experience?' To come up with a good design solution he concluded: 'you want to be able to sit in different places, dependent on the weather and other circumstances like sitting alone or in a group, so, the chair has to be light and easy to move'. He then explored the material needed: 'What material is light?' 'Of course wood is light, but probably the material surfboards are made of will be better.' In a parallel line of thought he added some requirements: 'Besides having a movable easy chair, you need some kind of table or 'tool' to put a glass of wine and a book on.' The designer coming up with the grass shape immediately concluded that he should ask a gardener how to make that shape.

Often, in an idea several domains are already included. The literally easy chair refers to an archetypical chair of wood and covering. The idea of a protected space refers to soft and warm material around you: the designer, making the enclosed, protected space in the large open area in the barn house, came up with a round object, hanging in the space, made of soft, warm material. On the other hand, it may also happen that studying one of the domains leads to unexpected insights. The designer, who wanted to make a flexible, springy shape, started with a massive flexible form and ended with an open zigzag form, caused by the fact that making the chair in this particular situation was not feasible.

\section{A frame of reference or library}

The act of designing takes place in a professional culture, in the context of the design tradition. Designers talk, sketch and think in patterns, in what is often called 'precedents' or 'references' (see Fig. 6). Cross (2007) points out that the knowledge designers are using, is embedded in the artificial world. The collected knowledge is analyzed and stored in images and diagrams. Designers build up a library or frame of reference, for use during the design process, within which the examples are used, tested in the situation at hand, 
rejected, transformed, and so on. Having a repertoire of patterns, they recognize or see certain elements as variants of experiences stored in their unconsciousness. Schön (1985) concludes that the designer has a repertoire of particular situations. These exemplars and images enable a designer to see a new situation, to a certain extend by constructing variations on familiar themes.

Chess players, as shown in research by De Groot (Lawson and Dorst 2009), seem to recognize, rather than analyze a situation. Playing against amateurs, they win the game, by using patterns. However, playing against opponents of the same level, they have to come up with something new, original and surprising. Lawson and Dorst conclude that we see expert designers do the same; they do not just solve problems, but add something new to the pool of precedents designers use.

This process of using and transforming is also illustrated by the different types of creativity Boden (1990) distinguishes: (1) making unfamiliar combinations of familiar ideas; generating, deliberately or unconsciously, poetic imagery, collages, analogies or associations. It requires a rich store of knowledge in the designer's mind and the capability of moving around with it in many different ways. (2) Exploring conceptual spaces; coming up with a new idea within a thinking style, within a culture. It is about seeing possibilities not noticed before, seeing the potential and pushing back frontiers in this thinking style. And (3) transforming the space; while exploring a structured conceptual space or thinking style, a new conceptual space emerges in your mind, which you could not have thought of before. It radically transforms the pre-existing style. Kneller (as cited in Lawson 2006: p. 157) formulates it this way: "One of the paradoxes of creativity is that, in order to think originally, we must familiarize ourselves with the ideas of others... these ideas can then form a springboard from which the creator's ideas can be launched."

Students do not only have to study all kinds of references, but they also have to learn (how) to work with them in their own design process.

In an overview of different studies, Cross (2001) concludes that expert designers frame or perceive problems in terms of relevant conjectures: they work with known, and previously applied patterns.

For example: Toyo Ito works in his Mediatheque with open floors, to achieve a fluent and flexible space. This pattern is also used by Le Corbusier in the Domino house and other
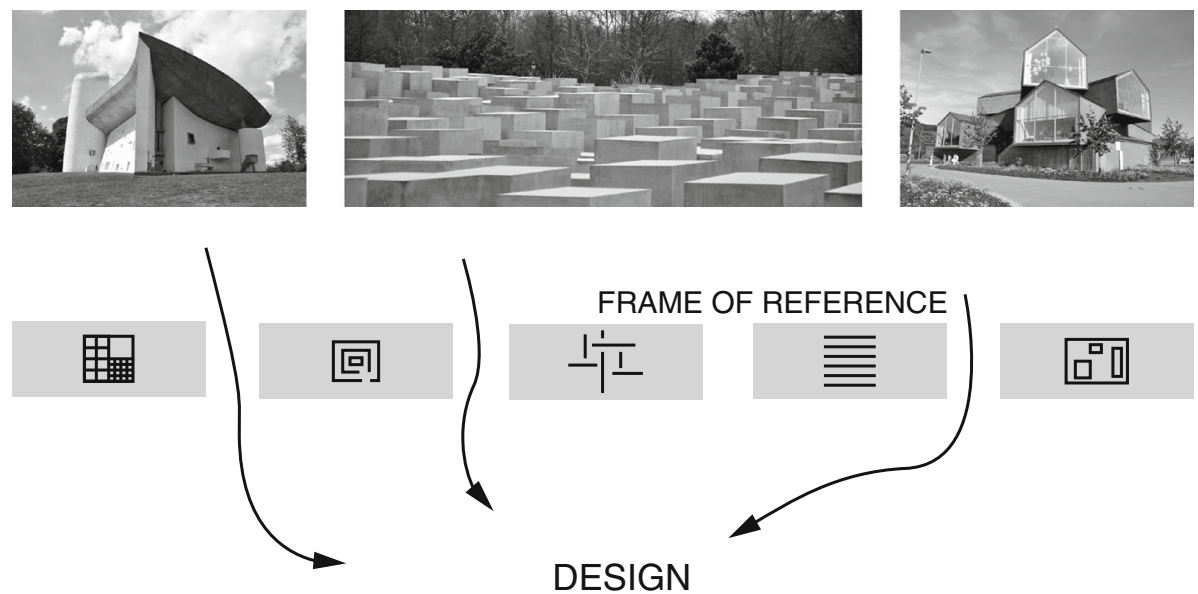

Fig. 6 Designing takes place in a professional culture, a frame of references (photographs by R. Maleki) 
architects such as Herzog and the Meuron and MVRDV. In these examples the structure varies from concrete columns to open compound steel columns. And somewhere a new pattern emerges; an architect discovers that bending and curving the floors connects these horizontal open spaces with each other much more fluently, creating a more vertical perception.

In the 15 min workshop, one designer associated the easy chair literally with a chair in an easy posture. She came up with an archetypical chair, yet, on a lazy or collapsed base.

Also other references were used: the designer who designed a place for meditating used ideas of minimalistic spaces and Zen gardens for meditation.

Most designers admitted afterwards that, though not having mentioned it during the design process, they did have an image of a chair in mind. It was either a vague general or 'combined' idea, or a specific chair.

\section{Laboratory or (visual) language}

Engineers have laboratories for experimenting. Designers have their own laboratory for the process of experimenting: the language of images. Apart from its function in presenting a design result, the visual language of sketching and modelling is a way of thinking out loud during the design process. Through the sketching and modelling, the design process unfolds (see Fig. 7).

The process of modelling and sketching runs parallel to the process of using words. Both languages capture meaning and are, to a certain extent, vague. They can express different meanings, which is an important feature in the open and creative design process.

Sketches and models are used as a way of reflective thinking, of understanding, analyzing and experimenting. They function as a visual way of making solutions explicit in order to understand them. In sketches and models, elements are analyzed by reducing and simplifying them. Designers "externalize some features of the design situation in order to examine them in a more focused way", to "stand back and look at them" (Lawson 2004: p. 46). In the process of sketching and modelling, the designer becomes aware of the implications of a choice. Sketching and modelling are processes of making choices, formulating, reformulating, and evaluating. In the process of experimenting, or 'web of moves', Schön (1985) describes the moves as changes in ideas and representations (configurations, sketches and words) and the implications of a move as traces of a drawing or model in the virtual world. While sketching and modelling, the designer explores the problem and possible solutions.

Expressing thoughts in the sketch and model, the designer also discovers new insights and new ideas. Often the processes of making explicit and expressing on paper or in a model brings about discoveries; the thought appears to be different when it becomes concrete in a sketch or model. The designer wonders what is happening. Seeing unexpected things happen, the designer starts reframing the situation at hand.

In the design process, designers also sketch to develop and capture what could be there. What Fraser and Henmi (Lawson 2004) call visionary drawings are speculative drawings. They are often considered to be art. They have the intention "to express wonderful or fantastic qualities. These drawings are not used to test an idea, but rather to let it flourish and develop so they are usually 'uncritical'."

Our conscious memory has a limited capacity. The sketches and models function as an external and extended memory, needed in a complex and interwoven process with all kinds of (provisional) decisions and implications. Pallasmaa sees the unity of mind and body as an important factor in craftsmanship and artistic work: "The knowledge and skills of 


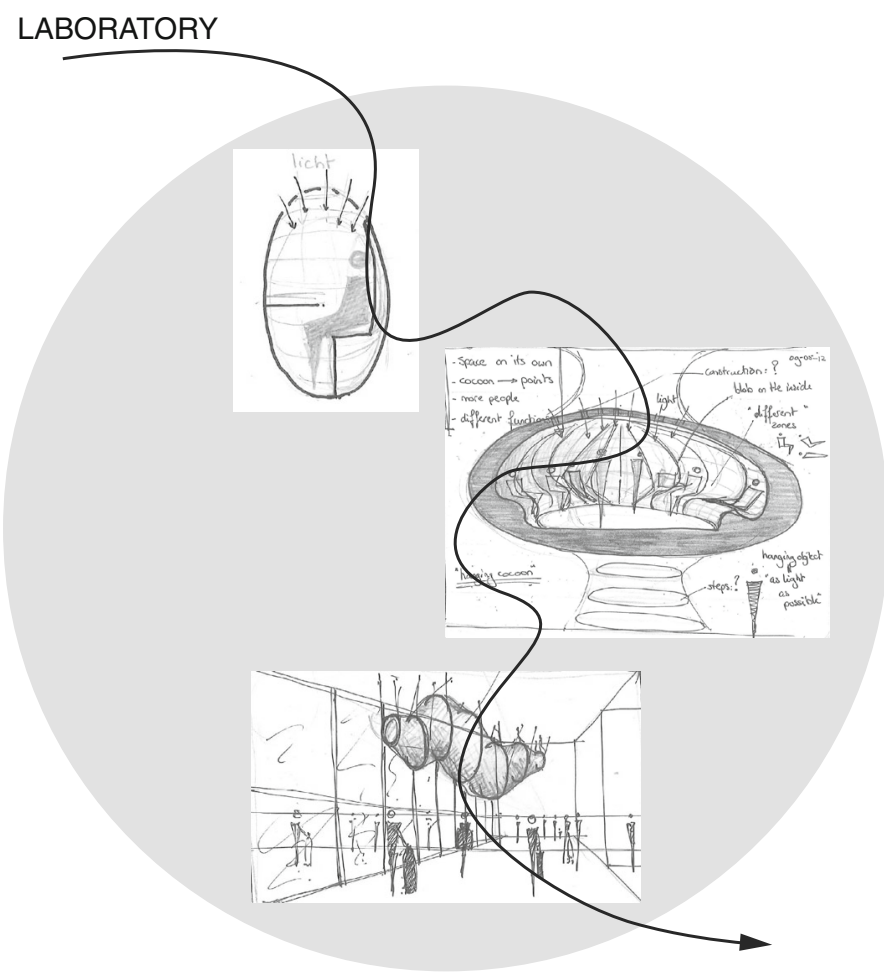

Fig. 7 The visual language of sketching and modelling functions as a laboratory for experimenting, it is a kind of physical thinking (sketches by R. Maleki, Designing an Abri)

traditional societies reside directly in the senses and muscles, in the knowing and intelligent hands, and are directly embedded and encoded in the settings and situations of life" (Pallasmaa 2009: p. 015). During the last few decades the idea of human consciousness as an embodied consciousness has been developing. Lakoff and Johnson (Anderson 2003) showed that our concepts of space-up, down, forward, back, on, in-are deeply tied to our bodily orientation to, and our physical movement in, the world. Gallese and Rizzolatti (Keysers 2012) showed that on a neural level there is a direct relation between what we see and what we do: the same neurons participate in both-previously thought separatesenses. Sketching and modelling seem to be more than an external memory and scale model of reality: they are embodied cognition.

For students learning to design, it is important to understand the role of sketching and modelling. Especially when they start, they consider designing as thinking, an act in the mind, and as coming up with a solution. Sketching and modelling, in their view, are meant for presenting the result. However, sketches and models function as a laboratory; they are the (three dimensional) tryouts during which the process of experimenting, of exploring and deciding takes place. Especially the three dimensional character of sketches (perspectives) and models and the process of abstracting in diagrams have to be trained by frequent doing, during the design process.

In the 'design a chair' workshop, the designers had to come up with a small paper/ cardboard/wooden sticks model in the end. Yet, even in the short time of $15 \mathrm{~min}$, some designers started with sketching. Other designers worked with the model, changing it in the 
process of experimenting. And some of them managed to make a set of a few small work models. They conduct their experiments with the help of sketches and models, or to put it in other words: in making the sketches and models they were answering their questions and testing their ideas.

\section{Conclusion and discussion}

\section{Making explicit the design process}

In this article we departed from the observation that, in the studio designing is learned in a process of learning-by-doing and that teachers mostly talk about the design product. Students may learn a lot from this approach. However, students who want to become designers have to learn about the process of designing. Therefore, the design process should also be part of the discussion. It means that the teacher should not only address the product, but also talk explicitly about the process, in order to teach the student the 'designerly' way of thinking.

Paying attention to the design process means talking about or questioning within the scope of the generic elements. What kind of experiments did you do? What are the implications, advantages and disadvantages of each alternative? Are the shape and the material you use in line with the guiding theme you want to achieve? Are there more alternatives to express this quality? Did you sketch perspectives? What references may be useful for the guiding theme and for the architectural means, needed to express the guiding theme?

\section{Construction}

The framework of the five generic elements seems to be a pragmatic and workable description of the design process. The elements describe, in very general terms, how expert designers work to come up with a design. They describe, in broad outline, the essential aspects of the design process. Being a scheme or construction, the framework may help in structuring and restructuring all the interwoven actions and aspects in the design process during the teaching and learning process. However, they certainly do not form a framework, which guarantees a (good) design outcome as long as you follow the rules.

The framework is a construction, an abstraction of the rich and differentiated design process. The generic elements offer a tool for making the design process explicit in a more systematic and structured way, without losing the open, creative and personal character of the design process. Reality is much richer and more differentiated. With formulating the generic elements, a process of exploring and explicating the richness and differentiation may be started.

Learning a complex skill is a matter of doing and becoming aware of what has to be done: it is a cyclical process of doing, experimenting, reflecting and understanding. The framework helps in becoming aware, in reflecting and understanding.

\section{Perspective}

It is hoped that explicitly knowing the broad outline of the design process and working explicitly with the generic elements in the design process, will lead to more understanding, 
for students and teachers alike. It should help design students to act more thoughtfully and be more focused.

For teachers, it would mean that they might educate the students in the design process in a more focused and structured way. Focusing on the generic elements, may lead to a better understanding of what students have to be trained in, where students get stuck and where the focus of attention should be in education. It may help train the total design skill and all different sub skills within a design course and it may help structure the curriculum.

For students, being more explicit in the design process may be helpful in the overall confusing learning process. To a certain extent, the framework may help in distinguishing and comparing the different approaches and methods expert designers use. Being more consciously aware of what designing is about, a student may get to grips with the 'open, personal, complex and creative' more easily. This may make her or him more independent in the design process.

The intertwined process of defining the generic elements by literature research, experimenting with them and further developing them in practice, will be continued. More detailed research will be conducted. The results will be subject of further research studies.

\section{References}

Anderson, M. L. (2003). Embodied cognition: A field guide. Artificial Intelligence, 149, 91-130.

Atman, C. J., \& Turns, J. (2001). Studying engineering design learning: Four verbal protocol studies. In C. Eastman, M. Newstetter, \& M. McCracken (Eds.), Design knowing and learning: Cognition in design education (pp. 37-60). Oxford: Elsevier Science.

Bielefeld, B., \& El Khouli, S. (2007). Design ideas. Basel: Birkhauser Verlag AG.

Boden, M. (1990). The creative mind: Myths and mechanisms. London UK: Weidenfeld and Nicholson.

Cross, N. (2001). Design cognition; Results from protocol and other empirical studies on design activity. In C. Eastman, M. Newstetter, \& M. McCracken (Eds.), Design knowing and learning: Cognition in design education (pp. 79-104). Oxford: Elsevier Science.

Cross, N. G. (2007). Designerly ways of knowing. Basel, Boston, Berlin: Birkhauser.

Csikszentmihalyi, M. (1996). Creativity, flow and the psychology of discovery and invention. New York: HarperCollins Publishers.

Darke, J. (1979). The primary generator and the design process. Design Studies, 1(1), 36-44.

Dreyfus, H. L., \& Dreyfus, S. E. (1986). Mind over machine, the power of human intuition and expertise in the era of the computer. New York: Free Press.

Eastman, C., Newstetter, M., \& McCracken, M. (Eds.). (2001). Design knowing and learning: Cognition in design education. Oxford UK: Elsevier Science.

Goldhoorn, B. (1991). Het atelier, analyse van een onderwijsmethode. Archis, 3, 49-51.

Keysers, C. (2012). Het empathische brein. Amsterdam: uitgeverij Bert Bakker.

Kolb, D. A. (1984). Experiental learning: Experience as the Source of learning and development. New Jersey: Prentice Hall.

Lawson, B. (1994). Design in mind. Oxford: Architectural Press.

Lawson, B. (2004). What designers know. Oxford: Architectural Press.

Lawson, B. (2006). How designers think, the design process demystified. Amsterdam: Architectural Press.

Lawson, B., \& Dorst, K. (2009). Design expertise. Oxford: Architectural Press.

Logister, L. (2005). John Dewey, een inleiding tot zijn filosofie. Budel: Uitgeverij Damon.

Newstetter, W. C., \& McCracken, W. M. (2001). Novice conceptions of design: Implications for the design of learning environments. In C. Eastman, M. Newstetter, \& M. McCracken (Eds.), Design knowing and learning: Cognition in design education (pp. 63-77). Oxford: Elsevier Science.

Oxman, R. (2001). The mind in design: A conceptual framework for cognition in design education. In C. Eastman, M. Newstetter, \& M. McCracken (Eds.), Design knowing and learning: Cognition in design education (pp. 269-295). Oxford: Elsevier Science.

Pallasmaa, J. (2009). The thinking hand. Existential and embodied wisdom in architecture. Chichester: Wiley.

Reigeluth, C. M. (Ed.). (1999). Instructional design theories and models. Mahwah, N.J.: Erlbaum. 
Ryle, G. (2002). The concept of mind. Chigaco: The University of Chicago Press (originally 1949, London). Schön, D. A. (1983). The reflective practitioner: How professionals think in action (Vol. 5126). Basic books. Schön, D. A. (1985). The design studio, an exploration of its traditions \& potential. London: RIBA publications Limited.

Schön, D. A. (1987). Educating the reflective practitioner: Toward a new design for teaching and learning in the professions. San Francisco: Jossey-Bass.

Schön, D. A., \& Wiggins, G. (1992). Kinds of seeing and their functions in designing. Design Studies, 13(2), $135-156$. 